Nanci Ferreira Pinto ${ }^{1}$

Neide Tiemi Murofuse ${ }^{1}$

Manoela de Carvalho ${ }^{2}$

\section{Processo e cargas de trabalho e a saúde dos trabalhadores na sericicultura: uma revisão}

\author{
Work process, workloads and workers' health in sericulture:
}

a review
${ }^{1}$ Universidade Estadual do Oeste do Paraná, Programa de Mestrado em Biociências e Saúde. Cascavel, PR, Brasil.

${ }^{2}$ Universidade Estadual do Oeste do Paraná, Programa de Mestrado em Saúde Pública em Região de Fronteiras. Foz do Iguaçu, PR, Brasil.

Contato

Nanci Ferreira Pinto

E-mail:

nanferpinto@gmail.com

O trabalho não é baseado em tese e não foi apresentado em reunião científica.

Os autores declaram não haver conflitos de interesses e que o trabalho não foi subvencionado.

\section{Resumo}

Introdução: sericicultura é a atividade de criação do bicho-da-seda (Bombyx mori). No Brasil é geralmente desenvolvida por pequenos agricultores. Objetivo: analisar a relação entre processo de trabalho e saúde-doença dos sericicultores. Métodos: revisão integrativa de literatura conduzida nas bases Medline, SciELO e Scopus e no banco de teses e de periódicos da CAPES. Resultados: quinze trabalhos atenderam aos critérios estabelecidos. Em nove desses estudos foi possível identificar o processo e as cargas de trabalho e nos outros seis, as doenças relacionadas à atividade. Identificaram-se como cargas de trabalho: físicas - umidade, ventilação, temperatura e intempéries; químicas - uso de adubos, formol, cal hidratada e fungicida; mecânicas - riscos de acidentes com equipamentos; orgânicas - fungos, bactérias, vírus e insetos; fisiológicas - esforço físico, trabalho noturno, jornadas prolongadas; psíquicas - ritmo e intensidade de trabalho, responsabilidade pela tarefa. Também foram relacionadas doenças respiratórias, alergias, irritação nos olhos, feridas, dores nas costas e de cabeça. Conclusão: apesar dos potenciais problemas relacionados à saúde dos trabalhadores da sericicultura, no Brasil não foram identificadas pesquisas voltadas especificamente a esse tema, mostrando a necessidade de realização de estudos para suprimir essa lacuna.

Palavras-chave: saúde do trabalhador; carga de trabalho; condições de trabalho; sericicultura; trabalhador rural.

\begin{abstract}
Introduction: sericulture is the activity of rearing silkworms (Bombyx mori). In Brazil it is usually developed by small farmers. Objective: to examine the relationship between work and health-disease process among sericiculturists. Methods: literature integrative review conducted in Medline, SciELO, Scopus and CAPES. Results: fifteen studies met the inclusion criteria; nine of them allowed the identification of processes and workloads related to this work activity, and the other six, the associated diseases. These studies identified as workloads: Physical - humidity, ventilation, temperature and weather; chemical - use of fertilizers, formaldehyde, hydrated lime and fungicide; mechanical - the risk of accidents with equipment; organic - fungi, bacteria, virus and insects; physiological - physical exertion, night work, long workday; work psychic - pace and intensity, task responsibility. There were also related respiratory diseases, allergies, eye irritation, injury, backaches and headaches. Conclusion: despite the potential problems relating to the health of sericulture workers, there are no researches specifically on this subject in Brazil, showing the need for further studies to fill the gaps.
\end{abstract}

Keywords: worker's health; workload; working conditions; sericulture; rural worker.
Recebido: $17 / 04 / 2014$

Revisado: 01/12/2014

Aprovado: 13/02/2015 


\section{Introdução}

O campo da Saúde do Trabalhador é uma área em construção no Brasil que compreende o trabalhador como sujeito central na busca pelo conhecimento do processo saúde-doença-trabalho (LACAZ, 2007) e na atuação para a promoção da sua saúde. Entende-se que a saúde-doença é determinada pelo modo como a sociedade produz e reproduz a vida. Ou seja, a forma de viver, adoecer e morrer em uma população se diferencia em relação às classes sociais (LAURELL; NORIEGA, 1989). Esse campo, ao incorporar princípios que colocam o trabalhador como sujeito no processo saúde-doença, se diferencia da Medicina do Trabalho e da Saúde Ocupacional, embora essas duas correntes sejam hegemônicas na área de saúde (LACAZ, 2007).

Segundo Laurell e Noriega (1989), os elementos fundamentais para entender os determinantes do processo saúde-doença dos trabalhadores são o objeto do trabalho, os instrumentos e o trabalho em si, os quais implicam duas vertentes nessa análise: uma técnica e outra social. Uma vez extraídas as características básicas dos objetos, dos instrumentos de trabalho e do trabalho em si, é preciso analisar as relações entre eles para reconstruir a dinâmica do processo de trabalho.

Na análise do processo de trabalho podem ser utilizadas duas categorias: as cargas e os desgastes. As cargas se dividem em dois grupos: as que têm materialidade externa ao corpo do trabalhador, como as cargas físicas, químicas, biológicas e mecânicas, e aquelas que só adquirem materialidade na corporeidade humana, ou seja, as cargas fisiológicas e psíquicas. Os efeitos das cargas físicas repercutem em acidentes e desenvolvimento de problemas, principalmente, biológicos. As cargas fisiológicas se expressam nas condições de trabalho que submetem o trabalhador, posturas, posições inadequadas, o esforço repetitivo etc. As cargas psíquicas podem ser do tipo que provocam tensão prolongada ou aquelas que causam sobrecarga psíquica - como atenção constante, ritmo, pressão por cumprimento de metas, cobrança e supervisão constante etc. As cargas atuam entre si no processo de trabalho e afetam o trabalhador (LAURELL; NORIEGA, 1989).

Ainda segundo o entendimento dos mesmos autores, o desgaste seria a "[...] perda da capacidade efetiva e/ou potencial, biológica e psíquica [...]" (LAURELL; NORIEGA, 1989, p. 115), resultado de processos adaptativos que acometem o trabalhador, levando ao adoecimento. A expressão do comprometimento da potencialidade psíquica e biológica não ocorre de forma direta e óbvia, dificultando o estabelecimento de nexo causal entre adoecimento mental e trabalho.
Nessa perspectiva, ressalta-se que as condições de saúde dos trabalhadores têm suas especificidades e que a compreensão de seus determinantes, bem como sua história e a evolução da sua prática, estão diretamente ligadas ao desenvolvimento da economia e das relações político-sociais. No entanto, o reconhecimento da relação existente entre as condições sociais e a saúde dos indivíduos não é um ponto pacífico, ao contrário, apresenta dificuldades e controvérsias, tornando necessário o desenvolvimento de estudos relativos à influência das condições de vida sobre a saúde.

Observa-se que a produção acadêmica no desvelamento do processo saúde-doença no trabalho, pelo campo da Saúde do Trabalhador, tem sido bastante profícua no Brasil. Santana (2006), em levantamento das teses e dissertações elaboradas por brasileiros em cursos de pós-graduação no Brasil e no exterior, no período de 1950 a 2004, identificou 1.025 documentos tendo como principais temas de pesquisa doenças osteomusculares, saúde mental e trabalhadores da saúde.

No entanto, muitas lacunas ainda persistem nesse campo do conhecimento, assim como o silêncio epidemiológico de muitos processos de adoecimento causados pelo trabalho. Um setor que não aparece nos estudos de saúde do trabalhador é a sericicultura. Essa atividade consiste na criação do bicho-da-seda (Bombyx mori) para a produção de casulos que serão utilizados como matéria-prima na produção de seda. No Brasil, envolve em torno de 2.500 pequenos agricultores familiares (BRATAC FIAÇÃ̃ DE SEDA, 2013) nos estados do Paraná, Santa Catarina, São Paulo e Mato Grosso do Sul (PARANÁ, 2013). A produção da seda é voltada principalmente para o mercado externo, sendo a atividade monopolizada no Brasil por uma empresa (BRASIL, 2013), que se relaciona com os produtores rurais através do sistema de dependência econômica denominado sistema integrado (PAULINO, 2003). Aspectos positivos como baixo impacto ambiental e diminuição do êxodo rural são atribuídos a essa atividade (BRANCALHÃO, 2002; TAKAHASHI et al., 2009).

Nessa perspectiva, aos militantes do campo da Saúde do Trabalhador ainda permanece atual o desafio de entender como o trabalho na sericicultura interfere na vida e na saúde das pessoas que o realizam, a fim de instrumentalizar a luta que envolve diferentes atores sociais e conflitos de interesse entre capital e trabalho.

Dessa forma, com o presente trabalho, buscou-se identificar nos estudos existentes alguns dos elementos disponíveis na literatura para a compreensão do processo e cargas de trabalho na sericicultura e sua relação com a saúde dos trabalhadores envolvidos nessa atividade. 


\section{Método}

O presente estudo se trata de uma revisão integrativa da literatura, a qual permite a inclusão de estudos com diferentes abordagens metodológicas, agrupando resultados obtidos de um conjunto de pesquisas primárias com temática idêntica ou similar. A principal finalidade desse tipo de pesquisa consiste em reunir e sintetizar os estudos realizados sobre um determinado assunto (SOUZA et al., 2010). A opção por esse método decorreu da possibilidade de sintetizar e analisar o conhecimento existente acerca da relação entre trabalho e saúde na sericicultura e obter subsídios que expliquem de maneira mais abrangente esse fenômeno específico.

Para o desenvolvimento desta revisão integrativa foram desenvolvidas as seguintes etapas: formulação do problema; busca e coleta de dados na literatura; avaliação dos dados; análise e apresentação da síntese do conhecimento e considerações finais.

A formulação do problema contemplou a definição das seguintes questões norteadoras: quais são as cargas e processos de trabalho dos trabalhadores na sericicultura? Que evidências já foram identificadas em relação ao processo saúde-doença na sericicultura?

A busca e a coleta na literatura foram realizadas nos meses de março a maio de 2013, utilizando-se das seguintes bases de dados: Literatura Internacional em Ciências da Saúde e Biomédica (MEDLINE), Biblioteca Científica Eletrônica On-line (SciELO), Portal Periódicos e Banco de Teses da Coordenação de Aperfeiçoamento de Pessoal de Nível Superior (CAPES) e base de dados referencial da Editora Elsevier nas áreas de Ciências Biológicas, Ciências da Saúde, Ciências Físicas e Ciências Sociais (SCOPUS). Foram utilizadas as palavras-chave: "sericicultura", "doença”, "bicho-da-seda", "doença ocupacional”, "sericiculture", "disease”, "ocupational disease", "enfermedad professional", "guzano de seda". As estratégias utilizadas para o levantamento dos artigos foram adaptadas para cada uma das bases de dados, de acordo com suas especificidades de acesso, tendo como eixo norteador a pergunta e os critérios de inclusão estabelecidos previamente.

Foram definidos os seguintes critérios de inclusão: a) artigos, teses e dissertações que apresentavam versão completa do estudo disponível on-line; b) textos escritos em português, inglês ou espanhol, independentemente do ano de publicação; c) que contemplassem elementos sobre a atividade da sericicultura, doenças do bicho-da-seda e dos sericicultores, cultivo da amoreira (Morus sp). Os critérios de exclusão foram: a) estudos indisponíveis na íntegra e on-line, b) estudos que apresentassem informações sobre alimentação, reprodução e genética do bicho-da-seda, aplicações da seda, ou seja, aqueles que não traziam informações em resposta às questões da pesquisa.

Para a avaliação dos dados e com a finalidade de extrair as informações dos artigos selecionados foi utilizado um instrumento específico com informações sobre título, autor(es), tipo de documento, ano, objetivo do trabalho, tipo de estudo, local, população/amostra, técnica de coleta de dados, resultados e conclusões.

Após a leitura dos estudos selecionados, a fim de identificar o processo e as cargas de trabalho da sericicultura, bem como as consequências para a saúde do trabalhador, os trechos dos estudos foram sistematizados e agrupados por similaridade temática em quatro categorias: caracterização dos artigos; relações de produção entre indústria e produtor rural na sericicultura; descrição das cargas e processo de trabalho; e doenças relacionadas à sericicultura.

Por fim, foi elaborado um texto sintético que contemplou as etapas percorridas para a elaboração da presente revisão e as principais contribuições extraídas dela, a fim de traçar um panorama acerca da problemática envolvida no cenário da sericicultura.

\section{Resultados e discussão}

Após uma primeira seleção, a partir da leitura criteriosa dos títulos e resumos, e exclusão dos documentos duplicados, foram selecionados 69 documentos. Desses, 15 artigos atenderam aos critérios definidos. Os 15 estudos incluídos nesta revisão apresentam diferentes características no que se refere à autoria e título, ao tipo de estudo, à referência e ano de publicação e ao local em que foram realizados os estudos (Quadro 1).

Ao analisar os estudos incluídos na revisão (Quadro 1), constata-se, em relação ao tipo de estudo, que os mais frequentes foram de pesquisa experimental (seis estudos) e pesquisa qualitativa (cinco estudos). Foram encontradas publicações que relacionam cargas e processos de trabalho nos anos de 1990 (três estudos) e aumento de publicações ao longo da década seguinte (12 estudos), especialmente com maior regularidade entre os anos de 2007 a 2013 (nove estudos). A explicação: o interesse desses estudos pela sericicultura pode estar relacionado a pesquisas que apontam a aplicação da seda na medicina (NOGUEIRA, 2010) e na estética (MARCELINO, 2008).

Os estudos analisados podem ser divididos em dois grupos: os de produção nacional e os de produção internacional. Os estados do Paraná (sete estudos) e São Paulo (três estudos) responderam pela produção nacional e trazem informações sobre as cargas e processos de trabalho; foram desenvolvidos pela Universidade Estadual de Maringá, Universidade 
Estadual Paulista, Universidade Estadual do Oeste do Paraná, Universidade Paranaense, Universidade Estadual de Londrina, Universidade Estadual Paulista.
O segundo grupo, produzidos no exterior, traz as evidências da relação dos processos de adoecimento com o trabalho na sericicultura.

Quadro 1 Caracterização dos trabalhos identificados em revisão integrativa de literatura como fonte de informações sobre cargas e processos de trabalho e relação saúde-doença na sericicultura

\begin{tabular}{|c|c|c|c|c|}
\hline Autor (ano) & Título da publicação & Tipo de estudo & Referência / ano & $\begin{array}{l}\text { Local do } \\
\text { estudo }\end{array}$ \\
\hline Oliveira (1990) & $\begin{array}{l}\text { O pequeno agricultor familiar e suas } \\
\text { relações com o complexo agroindustrial }\end{array}$ & $\begin{array}{l}\text { Estudo } \\
\text { documental }\end{array}$ & $\begin{array}{l}\text { Boletim de } \\
\text { Geografia / } 1990\end{array}$ & $\begin{array}{l}\text { Rio Claro, } \\
\text { São Paulo } \\
\end{array}$ \\
\hline $\begin{array}{l}\text { Nakazawa e Umegae } \\
(1990)\end{array}$ & $\begin{array}{l}\text { Sericulturist's lung disease: Hypertensitivity } \\
\text { pneumonitis related to silk production }\end{array}$ & Estudo de caso & Thorax / 1990 & $\begin{array}{l}\text { Maebashi, } \\
\text { Japão }\end{array}$ \\
\hline Wang et al. (1994) & $\begin{array}{l}\text { A study of occupational asthma and specific } \\
\text { IgE in sericulture workers }\end{array}$ & $\begin{array}{l}\text { Pesquisa } \\
\text { quantiqualitativa }\end{array}$ & $\begin{array}{l}\text { Zhongguo Yi Xue Ke Xue } \\
\text { Yuan Xue Bao / } 1994\end{array}$ & $\begin{array}{l}\text { Beijing, } \\
\text { China }\end{array}$ \\
\hline Brancalhão (2002) & $\begin{array}{l}\text { Vírus entomopatogênicos no } \\
\text { bicho-da-seda }\end{array}$ & $\begin{array}{l}\text { Pesquisa } \\
\text { experimental }\end{array}$ & $\begin{array}{l}\text { Biotecnologia, Ciência e } \\
\text { Desenvolvimento/ } 2002\end{array}$ & $\begin{array}{l}\text { Cascavel, } \\
\text { Paraná }\end{array}$ \\
\hline Miranda et al. (2002) & $\begin{array}{l}\text { Produção e qualidade de folhas de } \\
\text { amoreira em função da época do ano e de } \\
\text { colheita }\end{array}$ & $\begin{array}{l}\text { Pesquisa } \\
\text { experimental }\end{array}$ & Scientia Agrícola / 2002 & $\begin{array}{l}\text { Jaboticabal, } \\
\text { São Paulo }\end{array}$ \\
\hline Paulino (2003) & $\begin{array}{l}\text { Terra e Vida: A geografia dos camponeses } \\
\text { no norte do Paraná }\end{array}$ & $\begin{array}{l}\text { Pesquisa } \\
\text { qualitativa }\end{array}$ & $\begin{array}{l}\text { Tese (doutorado em } \\
\text { Geografia), Universidade } \\
\text { Estadual de } \\
\text { São Paulo/ } 2003\end{array}$ & \begin{tabular}{|l}
33 \\
municípios \\
produtores \\
de casulo \\
de seda do \\
norte do \\
Paraná \\
\end{tabular} \\
\hline Ataíde (2007) & $\begin{array}{l}\text { Diagnostico da atividade sericicola } \\
\text { na base territorial do Paraná centro e } \\
\text { identificação de gargalos tecnológicos }\end{array}$ & $\begin{array}{l}\text { Pesquisa } \\
\text { qualitativa }\end{array}$ & $\begin{array}{l}\text { Dissertação (mestrado em } \\
\text { Agronomia), Universidade } \\
\text { Estadual de } \\
\text { Londrina / } 2007\end{array}$ & $\begin{array}{l}17 \\
\text { municípios do } \\
\text { Paraná }\end{array}$ \\
\hline Meneguim et al. (2007) & $\begin{array}{l}\text { Influencia de cultivares de amoreira } \\
\text { (Morus spp) sobre a produção e qualidade } \\
\text { de casulos de bicho-da-seda, Bombyx mori } \\
\text { L. (lepidoptera: bombycidae) }\end{array}$ & $\begin{array}{l}\text { Pesquisa } \\
\text { experimental }\end{array}$ & $\begin{array}{l}\text { Neotropical } \\
\text { Entomology / } 2007\end{array}$ & $\begin{array}{l}\text { Londrina, } \\
\text { Paraná }\end{array}$ \\
\hline Cunha (2007) & $\begin{array}{l}\text { Análises técnica e energética da secagem } \\
\text { combinada no processamento de casulo } \\
\text { do bicho-da-seda de Bombyx mori L. }\end{array}$ & $\begin{array}{l}\text { Pesquisa } \\
\text { experimental }\end{array}$ & $\begin{array}{l}\text { Dissertação (mestrado em } \\
\text { Agronomia), Faculdade } \\
\text { de Ciências Agronômicas, } \\
\text { Botucatu/ } 2007\end{array}$ & $\begin{array}{l}\text { Duartina, } \\
\text { São Paulo }\end{array}$ \\
\hline Munhoz et al. (2009) & $\begin{array}{l}\text { A influência de cultivares de amoreiras } \\
\text { adubadas sobre características biológicas } \\
\text { e produtivas do bicho-da-seda (Bombyx } \\
\text { mori L) }\end{array}$ & $\begin{array}{l}\text { Pesquisa } \\
\text { experimental }\end{array}$ & $\begin{array}{l}\text { Arquivos de Ciências } \\
\text { Veterinárias e Zoologia da } \\
\text { UNIPAR / } 2009\end{array}$ & $\begin{array}{l}\text { Nova } \\
\text { Esperança, } \\
\text { Paraná }\end{array}$ \\
\hline Liu et al. (2009) & $\begin{array}{l}\text { Identification and Characterization of an } \\
\text { Arginine Kinase as a Major Allergen from } \\
\text { Silkworm (Bombyx mori) Larvae }\end{array}$ & $\begin{array}{l}\text { Pesquisa } \\
\text { experimental }\end{array}$ & $\begin{array}{l}\text { International Archives of } \\
\text { Allergy and } \\
\text { Immunology/2009 }\end{array}$ & China \\
\hline Santos et al. (2011) & $\begin{array}{l}\text { A criação do Bombyx mori (bicho-da-seda) } \\
\text { e as principias doenças }\end{array}$ & Revisão & $\begin{array}{l}\text { Arquivos de Ciências } \\
\text { Veterinárias e Zoologia da } \\
\text { UNIPAR / } 2011\end{array}$ & $\begin{array}{l}\text { Umuarama, } \\
\text { Paraná }\end{array}$ \\
\hline Wani e Jaiswal (2011) & $\begin{array}{l}\text { Health hazards of rearing silk worms and } \\
\text { environmental impact assessment of rearing } \\
\text { households of Kashmir, India }\end{array}$ & $\begin{array}{l}\text { Pesquisa } \\
\text { qualitativa }\end{array}$ & $\begin{array}{l}\text { Indian Journal of Public } \\
\text { Research and } \\
\text { Development / } 2011\end{array}$ & $\begin{array}{l}\text { Kashmir, } \\
\text { Índia }\end{array}$ \\
\hline Sabbag et al. (2013) & $\begin{array}{l}\text { Custos e viabilidade econômica da } \\
\text { produção de casulos do bicho-da-seda }\end{array}$ & $\begin{array}{l}\text { Pesquisa } \\
\text { qualitativa }\end{array}$ & $\begin{array}{l}\text { Pesquisa Agropecuária } \\
\text { Tropical, Goiânia / } 2013\end{array}$ & $\begin{array}{l}\text { Bastos, } \\
\text { São Paulo }\end{array}$ \\
\hline $\begin{array}{l}\text { Vijayabhaskararao et al. } \\
\text { (2013) }\end{array}$ & $\begin{array}{l}\text { An epidemiological and environmental survey } \\
\text { on occupational health hazards during silk } \\
\text { production and processing }\end{array}$ & $\begin{array}{l}\text { Pesquisa } \\
\text { qualitativa }\end{array}$ & $\begin{array}{l}\text { Environmental Health 2013, } \\
\text { Science and Policy to protect } \\
\text { future generations, } \\
\text { USA / } 2013\end{array}$ & Índia \\
\hline
\end{tabular}


Em relação aos estudos estrangeiros, observou-se que fazem relação do trabalho com a saúde e que foram realizados nos países maiores produtores de seda: China, Japão, Índia.

Com relação aos trabalhos nacionais identificados, os mesmos não tratam da saúde dos trabalhadores. A unidade da Federação de origem desses trabalhos são estados produtores de bicho-da-seda: São Paulo foi o maior responsável pela produção de casulos até meados da década de 1980 e, a partir de então, o Paraná tem se destacado na produção, respondendo atualmente por $89 \%$ da produção nacional, conforme dados da safra de 2012/2013 (PARANÁ, 2013).

\section{As relações de produção na sericicultura}

O Brasil é o quinto produtor mundial de seda (PAULINO, 2003) e o estado do Paraná, o maior produtor nacional. Segundo Santos et al. (2011), a migração da atividade da sericicultura para o Paraná se deu pelo envelhecimento das amoreiras em São Paulo e pela falta de incentivo do governo estadual para a atividade. Porém, informe do IBGE (INSTITUTO BRASILEIRO DE GEOGRAFIA E ESTATÍSTICA, 2011) atribui a desistência dos produtores paulistas ao baixo retorno econômico.

A criação do bicho-da-seda tem sido estimulada pelo estado do Paraná e municípios produtores na perspectiva da criação de postos de trabalho, por meio de incentivos financeiros, linhas de crédito e apoio com infraestrutura (PAULINO, 2003; SANTOS et al., 2011).

A sericicultura é uma atividade sob o controle do complexo agroindustrial, cujas empresas detêm as matrizes do bicho-da-seda e as estratégias de cruzamento para obter raças híbridas, assim como o processo de beneficiamento dos casulos de seda (PAULINO, 2003).

De acordo com Sabbag et al. (2013), os cálculos dos custos de produção e de rentabilidade podem variar, considerando o tamanho da propriedade, disponibilidade de mão de obra, recursos para investimentos iniciais e preço final.

Embora a sericicultura seja uma atividade que propicie rentabilidade, ela não se desenvolve durante o ano todo e se realiza apenas durante os meses compreendidos entre setembro e maio, oportunizando aos sericicultores a diversificação de produção na propriedade. Além disso, a produção do fio de seda é destinada à exportação e está submetida aos ciclos de expansão e retração do mercado externo, sendo a China o maior produtor mundial (PAULINO, 2003). A seda crua é uma commodity comercializada nos mercados de Lion, Londres e Nova Iorque (PARANÁ, 2013). Assim, a formação do preço das commodities ocorre a partir das bolsas de mercadorias e sofre influência da taxa de câmbio (BRASIL, 2011).

A partir da compreensão da centralidade da categoria trabalho na investigação sobre o processo saúde-doença em coletivos humanos, é preciso considerar que se trata de um processo que envolve não apenas as condições biológicas, mas os diversos elementos que contribuem para a vida humana, tanto do ponto de vista material quanto subjetivo, incluídos os determinantes históricos, econômicos, sociais e culturais. Nesse sentido, entende-se o trabalho como categoria fundamental para a discussão sobre o adoecimento em seu caráter social, que transcende o aspecto biológico e é determinado pela inserção dos grupos humanos no processo de produção, como afirmam Laurell e Noriega (1989). Nessa perspectiva, apresentam-se, a seguir, elementos da atividade da sericicultura que se relacionam com esses aspectos.

\section{Relações de produção}

- Não existe um contrato de compromisso entre o produtor e a indústria, pois a indústria tem o monopólio do mercado de seda (OLIVEIRA, 1990).

- Os trabalhadores na condição de proprietários, integraram-se ao mercado como fornecedores de matéria-prima, subordinando-se às indústrias como produtores autônomos ou associados a cooperativas (OLIVEIRA, 1990).

- A subordinação às indústrias se dá por financiamento para insumos, assistência técnica, pagos quando da entrega dos produtos, classificados pelo padrão de qualidade (OLIVEIRA, 1990).

- A relação dos produtores com a empresa é feita pelo sistema de integração (PAULINO, 2003).

- As transações entre os produtores rurais, fornecedores dos casulos verdes, e as indústrias do setor se dão exclusivamente por venda direta e são marcadas pela ligação condicionada pelo ciclo biológico da produção (ATAÍDE, 2007).

\section{Custos/linhas de crédito/taxa de lucro}

- Os produtores pagam um valor superior ao de mercado pelos insumos (OLIVEIRA, 1990).

- Há desconhecimento pelos produtores do custo da produção (OLIVEIRA, 1990).

- A utilização da força de trabalho da família não é computada como despesa no cálculo do custo da produção (OLIVEIRA, 1990).

-Baixo custo de implantação da atividade 
(PAULINO, 2003).

- A taxa de lucro da empresa se dá à medida que não paga todo o trabalho da família contido nos casulos (PAULINO, 2003).

- As empresas recorrem a linha de credito Agregação de Renda a Atividade Rural vinculada ao Programa Nacional de Fortalecimento da Agricultura Familiar e se colocam como intermediárias (PAULINO, 2003).

- A qualidade do casulo (tamanho, forma e limpeza) e das propriedades são critérios de permanência na atividade (PAULINO, 2003).

- O cálculo dos custos de produção e a rentabilidade é variável, considerando o tamanho da propriedade, disponibilidade de mão de obra direta, recursos para investimentos iniciais e preço final (SABBAG et al., 2013).

- A lucratividade de produção de casulos é superior a outros produtos como milho, pecuária bovina e leiteira (SABBAG et al., 2013).

- Custo total de produção de R\$10.382,81 para uma produção de 1.904 kg ano (SABBAG et al., 2013).

- Atividade com lucratividade superior a 50\% para o ciclo produtivo (SABBAG et al., 2013).

- Apresenta Taxa Interna de Retorno superior ao custo do capital (SABBAG et al., 2013).

- Governos estaduais disponibilizam crédito de financiamento (SANTOS et al., 2011).

Pagamento ao produtor

- Após estipulado o preço do quilo do casulo e determinado o total da produção é efetuado o pagamento, após descontar os insumos e as larvas (OLIVEIRA, 1990).

- Os negócios são formalizados por intermédio de notas fiscais que chegam ao produtor com as larvas, com identificação do nome do produtor, e quando da entrega dos casulos (OLIVEIRA, 1990).

- O cálculo do pagamento dos casulos pelo produtor centra-se no teor da seda, porém a empresa consegue agregar no processamento industrial o aproveitamento integral dos casulos; as larvas, mortas por choque térmico para evitar a evolução das crisálidas, possuem propriedades proteicas e são aproveitadas na fabricação de ração para peixes; a parte final dos casulos, que não permite a extração da seda em forma de fio, é submetida a processo de fiação associada a fios de algodão, dando origem à viscose (PAULINO, 2003).
Na relação com a empresa, os trabalhadores, na condição de pequenos proprietários rurais, integram-se ao mercado como fornecedores de matéria-prima, subordinando-se às indústrias como produtor autônomo ou associado a cooperativa (OLIVEIRA, 1990), sendo a atividade condicionada pelo ciclo biológico do bicho-da-seda (ATAÍDE, 2007). O sistema de integração, embora não regulamentado no Brasil, é bastante utilizado pelas indústrias da alimentação e do tabaco. Esse sistema tem sido denunciado pelas organizações de trabalhadores e Ministério Público uma vez que esconde uma relação de emprego. Além disso, é um processo que impõe uma situação de endividamento para muitos produtores, o que Almeida (2005) trata como um "contrato de servidão". Em relação aos contratos de integração na produção do fumo, em 2007 o Ministério Público do Trabalho do Estado do Paraná ajuizou seis Ações Civis Públicas (ACP) contra as indústrias fumageiras, Associação dos Fumicultores do Brasil (AFUBRA) e o Sindicato das Indústrias do Fumo (SINDIFUMO), devido à existência de trabalho degradante, falta de registro dos trabalhadores e uso de mão de obra infantil (JUSBRASIL, 2007).

$\mathrm{Na}$ sericicultura, a empresa fornece as lagartas, materiais e os insumos utilizados, tanto para a lavoura quanto para o barracão. Todo o processo de produção é acompanhado por meio da assistência técnica disponibilizada pela empresa. Os produtores referem pagamento de valor superior ao de mercado pelos insumos, assim como desconhecimento do custo da produção (OLIVEIRA, 1990). A empresa ainda pode financiar a construção dos barracões, sendo que os custos são descontados na contraentrega dos casulos ressaltando-se a inexistência de contrato formal entre as empresas e os produtores, apenas o compromisso de entrega da produção para a empresa (PAULINO, 2003; ATAÍDE, 2007).

Há uma relação desigual entre empresa e produtores. Os produtores não têm controle sobre a forma de produzir e o preço da produção é estipulado pela empresa a partir da avaliação da qualidade dos casulos, realizada a partir de critérios estabelecidos unilateralmente pela empresa (PAULINO, 2003). Embora o cálculo do pagamento dos casulos seja centrado no teor da seda, a empresa consegue agregar no processamento industrial o aproveitamento das crisálidas como ração animal, que é exportada para outros países (BRATAC FIAÇÃO DE SEDA, 2002). Segundo Paulino (2003) há também o uso dos casulos não aproveitados na extração da seda para a produção de viscose.

Outro elemento de subordinação à empresa diz respeito ao financiamento, via linha de crédito intitulada Agregação de Renda à Atividade Rural (AGREGAR), vinculada ao Programa Nacional de Fortalecimento da Agricultura Familiar (PRONAF), acessado pelas empresas (PAULINO, 2003). Nesse processo, a empresa 
se beneficia em dois aspectos: na subordinação dos produtores que, ao acessarem essa linha de crédito, ficam impossibilitados de receber financiamento para outras atividades produtivas, e no acesso ao fundo público com baixo custo monetário, por meio do financiamento ao pequeno produtor (PAULINO, 2003).

O aumento da taxa de lucro, que se dá pelo não pagamento da mão de obra do trabalho de toda a família, é outro elemento que favorece as empresas (OLIVEIRA, 1990; PAULINO, 2003). Assim, o não estabelecimento de vínculo empregatício pela empresa implica o não acesso pelos trabalhadores a uma série de direitos relacionados ao trabalho, como pagamento de horas extras, trabalho noturno, férias, $13^{\circ}$ salário, vigilância da saúde e segurança.

No que concerne a outros fatores que interferem na atividade, os estudos indicam problemas relacionados ao ritmo do trabalho, que altera o modo de vida das famílias, à oscilação do mercado e ao uso de agrotóxicos em áreas próximas aos barracões, que podem causar a morte dos bichos-da-seda (PAULINO, 2003).

\section{Processo e cargas de trabalho na sericicultura}

Considerando que os modos de produção na sericicultura em diferentes países guardam singularidades relacionadas ao processo de trabalho e de produção em cada região, a metodologia utilizada neste estudo apresenta limitações quanto às generalizações em relação às doenças descritas nos estudos internacionais. Procurou-se ressaltar, aqui, questões que têm respaldo nas cargas e processos de trabalho descritos nos estudos brasileiros.
No Quadro 2 podem-se visualizar os principais aspectos relacionados às tarefas e à carga de trabalho identificados nos estudos brasileiros incluídos neste trabalho de revisão de literatura, em relação à atividade da sericicultura.

O ciclo de vida do bicho-da-seda, na fase larval, corresponde a cinco idades, as duas primeiras se completam na indústria e da terceira à quinta idade as lagartas são criadas pelos produtores rurais (PAULINO, 2003; ATAÍDE, 2007; SABBAG et al., 2013). A criação das lagartas é realizada em barracões (sirgarias), onde são colocadas em esteiras de criação de forma suspensa ou no chão (ATAÍDE, 2007). Os cuidados com o bicho-da-seda consistem na alimentação, limpeza, higienização dos barracões, manejo das larvas na fase de encasulamento e limpeza dos casulos (OLIVEIRA, 1990; PAULINO, 2003; ATAÍDE, 2007; SABBAG et al., 2013).

A qualidade da produção dos casulos de seda está diretamente relacionada à alimentação das larvas, que é feita exclusivamente com folhas de amoreira (MIRANDA et al., 2002; PAULINO, 2003; ATAÍDE, 2007; MENEGUIM et al., 2007; MUNHOZ et al., 2009). A frequência da alimentação varia conforme a idade da larva: três vezes ao dia, na terceira idade; quatro vezes ao dia, na quarta idade; e sete vezes ao dia, na quinta idade (ATAÍDE, 2007), com intensificação do consumo de folhas pelas larvas no período da manhã e da noite (PAULINO, 2003). Portanto, a última semana de cada lote de criação representa uma grande sobrecarga de atividade física para os sericicultores, decorrente do aumento significativo de consumo de alimento pelas lagartas.

Quadro 2 Síntese das atividades, tarefas e cargas de trabalho na sericicultura identificadas em estudos realizados no Brasil

\begin{tabular}{|c|c|c|c|}
\hline Atividade & Autor (ano) & Tarefas identificadas & Cargas identificadas neste estudo \\
\hline Cultivo da amoreira & $\begin{array}{l}\text { Miranda et al. (2002) } \\
\text { Paulino (2003) } \\
\text { Ataíde (2007) } \\
\text { Meneguim et al. (2007) }\end{array}$ & $\begin{array}{l}\text { Adubação, podas, corte de } \\
\text { galhos, controle de ervas } \\
\text { daninhas, transporte de } \\
\text { galhos }\end{array}$ & $\begin{array}{l}\text { Físicas: umidade, temperatura, } \\
\text { intempéries; } \\
\text { Químicas: adubos químicos, agrotóxicos; } \\
\text { Orgânicas: bactérias, fungos; } \\
\text { Mecânicas: riscos de acidentes com } \\
\text { equipamentos; } \\
\text { Fisiológicas: esforço físico, jornadas } \\
\text { prolongadas de trabalho. }\end{array}$ \\
\hline Criação do bicho-da-seda & $\begin{array}{l}\text { Oliveira (1990) } \\
\text { Brancalhão (2002) } \\
\text { Paulino (2003) } \\
\text { Ataíde (2007) } \\
\text { Santos et al. (2011) } \\
\text { Sabbag et al. (2013) }\end{array}$ & $\begin{array}{l}\text { Disposição das larvas, } \\
\text { higienização da sirgaria, } \\
\text { alimentação das larvas, } \\
\text { manejo no processo } \\
\text { de emboscamento } \\
\text { (encasulamento das larvas), } \\
\text { limpeza e classificação dos } \\
\text { casulos }\end{array}$ & $\begin{array}{l}\text { Físicas: umidade, temperatura, ventilação; } \\
\text { Químicas: formol, cal hidratado, fungicida; } \\
\text { Orgânicas: fungos, bactérias, vírus, insetos; } \\
\text { Mecânicas: riscos de acidentes com } \\
\text { equipamentos; } \\
\text { Fisiológicas: esforço físico, jornadas } \\
\text { prolongadas de trabalho, trabalho } \\
\text { noturno; } \\
\text { Psíquicas: ritmo e intensidade de trabalho; } \\
\text { responsabilidade pela tarefa. }\end{array}$ \\
\hline
\end{tabular}


No cultivo da amoreira, o preparo da terra e os tratos culturais são executados com tração manual, animal ou tratorizada. A adubação é mineral e/ou orgânica (ATAÍDE, 2007; MENEGUIM et al., 2007). Para a realização das podas nos meses de junho, julho e agosto são utilizados equipamentos como, por exemplo, foice, tesoura de poda. O verão é o período mais propício para uma melhor produção das folhas (MIRANDA et al., 2002). A operação de colheita das folhas é realizada com predominantemente de forma semimanual, que consiste em cortar ramos com foice, facão e tesoura de poda (ATAÍDE, 2007). Essa atividade é crucial para a alimentação das lagartas e é realizada em qualquer condição climática. O transporte dos galhos para a sirgaria ou para o depósito de folhas é realizado de forma braçal e/ou por carroça.

Na realização das diversas tarefas como adubação, podas, corte de galhos, controle de ervas daninhas e transporte de galhos, os trabalhadores são expostos a produtos químicos (adubos), bactérias, fungos, intempéries, riscos de acidentes com equipamentos e esforço físico pelo trabalho manual e prolongado.

Existem máquinas e equipamentos que podem diminuir o esforço físico necessário à realização de diversas tarefas para a criação do bicho-da-seda, o que facilitaria significativamente o trabalho dos sericicultores. Porém, é importante salientar que o acesso a essas tecnologias via financiamento público está vinculado ao pacote do sistema de integração.

No processo de criação do bicho-da-seda, as atividades realizadas incluem a disposição das larvas sobre estruturas que podem ficar no chão ou suspensas, higienização da sirgaria, alimentação constante das larvas, cuidados com as larvas, manejo do processo de encasulamento, limpeza e classificação dos casulos.

Para o controle de vetores e de doenças nas lagartas é realizada a desinfecção da sirgaria com a pulverização de produtos químicos como formol, cal hidratada e fungicida (PAULINO, 2003; ATAÍDE, 2007; SABBAG et al., 2013). As doenças que podem infectar o bicho-da-seda são transmitidas por protozoários, bactérias e fungos (SANTOS et al., 2011; BRANCALHÃO, 2002). Em relação à exposição a produtos químicos, o formol é utilizado no processo de desinfecção das sirgarias e está classificado desde 2004 pela Internacional Agency for Research on Cancer (IARC) da Organização Mundial da Saúde como carcinogênico (Grupo1), tumorogênico e teratogênico, por produzir efeitos na reprodução para humanos e para algumas espécies de animais (INSTITUTO NACIONAL DO CANCER, 2013). Ou seja, não há níveis seguros à sua exposição. A Norma Regulamentadora 15 do Ministério do Trabalho e Emprego considera o formol como grau máximo de insalubridade (BRASIL, 1978). A Norma Regulamentadora 31 estabelece também uma série de parâmetros e exigências para o trabalho na agricultura (BRASIL, 2005), porém como os produtores familiares são considerados autônomos, não são protegidos por essa legislação.

Na quinta idade do bicho-da-seda ocorre o processo de emboscamento, quando as larvas se alocam em espaços individuais, nos bosques, para a produção dos casulos. Durante quatro a cinco dias, os produtores realizam cuidados manuais de manejo para que haja apenas uma lagarta por espaço (ATAÍDE, 2007). Os períodos com maior intensidade de alimentação do bicho-da-seda são pela manhã e pela noite, inclusive com relato de trabalho noturno (PAULINO, 2003).

A colheita dos casulos é realizada manualmente, com a utilização de garfos, e devem ser observados cuidados para não manchar e amassar os casulos. Também é feita uma pré-seleção dos casulos pelos produtores, observando-se tamanho, peso e limpeza (PAULINO, 2003; ATAÍDE, 2007).

A empresa classifica os casulos como de primeira, que são os homogêneos, consistentes e limpos, e de segunda, os calcinados, com manchas externas, crisálidas não formadas, com defeitos de bosques ou os duplos mal formados (OLIVEIRA, 1990; CUNHA, 2007).

Para a realização da atividade da sericicultura há a necessidade do envolvimento de todo o grupo familiar, incluindo as crianças e os idosos (PAULINO, 2003), assim como uma participação importante das mulheres (ATAÍDE, 2007). Embora os estudos chamem a atenção para o trabalho das crianças e da mulher, não indicam quais são as atividades que esses dois grupos realizam.

O estabelecimento de critérios cada vez mais rigorosos pelas empresas para a produção implica diretamente em mudanças no modo de vida das famílias envolvidas na atividade, inclusive impedindo o lazer e o convívio social (PAULINO, 2003).

Em síntese, para as atividades de manejo da criação, os trabalhadores têm como cargas a exposição à umidade, ao trabalho noturno, às substâncias químicas (cal, formol), a fungos e bactérias, ao esforço físico, ao risco de acidente com equipamentos, ao ritmo intenso na atividade, principalmente na quinta idade das lagartas, e à pressão para a qualidade da produção pela indústria.

\section{Relação saúde-doença na sericicultura}

Apesar de nenhum estudo ter abordado a questão dos acidentes e doenças do trabalho, é importante chamar atenção para as pesquisas que evidenciam a ocorrência de acidentes de trabalho na atividade rural. Fehlberg et al. (2001), em estudo sobre acidentes de trabalho na zona rural de Pelotas, no Rio Grande do Sul, identificaram que os acidentes causados por 
Quadro 3 Agravos à saúde relacionados ao trabalho na sericicultura, identificados em literatura estrangeira

\begin{tabular}{|l|l|}
\hline \multicolumn{1}{|c|}{ Autor (ano) } & \multicolumn{1}{|c|}{ Evidências sobre o processo saúde-doença relacionado ao trabalho } \\
\hline Nakazawa e Umegae (1990) & $\begin{array}{l}\text { - O bicho-da-seda induz à hipersensibilidade para pneumonite. } \\
\text { - Sugere que a doença seja chamada “doença pulmonar do sericultor”. }\end{array}$ \\
\hline Wang et al. (1994) & - Sintomas alérgicos respiratórios em trabalhadores da sericicultura \\
\hline Liu et al. (2009) & - Alergias \\
\hline Wani e Jaiswal (2011) & - Irritação nos olhos, feridas, dor nas costas, alergias, problemas respiratórios e dores de cabeça \\
\hline $\begin{array}{l}\text { Vijayabhaskararao et al. } \\
(2013)\end{array}$ & - Tosse e alergias \\
\hline
\end{tabular}

ferramentas manuais e animais domésticos foram os mais frequentes. Faria et al. (2000), em estudo com trabalhadores da região serrana do Rio Grande do Sul também identificaram a ocorrência de acidentes de trabalho envolvendo o trabalho agrícola.

Embora não tenham sido encontrados artigos sobre o processo saúde-doença dos trabalhadores da sericicultura no Brasil, foram identificados estudos no Japão, China e Índia que evidenciam doenças relacionadas ao trabalho nessa atividade (Quadro 3).

Estudo de caso no Japão (NAKAZAWA; UMEGAE, 1990), demonstrou que o bicho-da-seda pode induzir hipersensibilidade para pneumonite. Um trabalho realizado em Beijing identificou sintomas de alergia respiratória na sericicultura em $75 \%$ dos trabalhadores examinados (WANG et al., 1994).

Uma pesquisa epidemiológica e ambiental sobre riscos de saúde ocupacional na produção e transformação da seda na Índia (VIJAYABHASKARARAO et al., 2013) identificou a ocorrência de tosse, resfriados e alergias. Ainda na Índia foram encontrados problemas de saúde entre os criadores do bicho-da-seda como irritação nos olhos, feridas, dor nas costas, alergias, problemas respiratórios e dores de cabeça (WANI; JAISWAL, 2011).

No Brasil, ao lado da dificuldade para o estabelecimento do nexo causal da enfermidade com o trabalho, persiste o problema da subnotificação. O subdimensionamento da prevalência, em nosso país, das doenças ocupacionais em geral, e em especial as pulmonares, implica em prejuízo nas estratégias de prevenção e vigilância epidemiológica da saúde do trabalhador.

A falta de dados sobre a exposição dos sericicultores tanto aos produtos químicos (em especial o formol, produto reconhecidamente cancerígeno pela IARC) quanto a material biológico indica uma lacuna de pesquisa importante para a proteção da saúde desses trabalhadores.

Essa carência de dados sobre o adoecimento na atividade da sericicultura nos remete aos estudos de Correa (2008), em relação ao benzenismo em trabalhadores do setor petroquímico; aos estudos sobre as doenças ocupacionais respiratórias de Silvestre e Capitani (2010); e à pesquisa de Rezende (2005), que indica a existência de um silêncio epidemiológico em relação à saúde dos trabalhadores. Ou seja, as condições de vida e trabalho, ao não serem desvendadas, dificultam o reconhecimento da relação entre os processos de saúde e doença dos trabalhadores e as condições de vida/trabalho.

Ainda que os estudos internacionais chamem a atenção para os problemas relativos ao adoecimento em sericicultores, é preciso alertar que, por se tratar de condições de produção diferentes das adotadas no Brasil, estudos futuros poderão aprofundar as realidades de produção existentes em diversos países.

\section{Conclusões}

Não foram identificados estudos brasileiros relacionados à saúde do trabalhador da sericicultura. No entanto, as publicações nacionais e internacionais levantadas no presente estudo permitiram identificar que o processo e as cargas de trabalho na atividade da sericicultura podem gerar acidentes e doenças relacionadas ao trabalho, envolvendo doenças respiratórias, infecciosas e parasitárias, dos olhos, da pele, do sistema nervoso, do sangue e distúrbios osteomusculares, bem como transtornos mentais e comportamentais.

A exposição dos sericicultores às diversas cargas de trabalho merece atenção no sentido de se buscar implementar medidas efetivas para prevenir doenças, com especial destaque para a exposição química ao formol, que deve ser urgentemente dimensionada e monitorada pelos serviços de saúde. Também destacam-se os elementos ergonômicos relativos ao esforço físico, a jornadas prolongadas, ao trabalho noturno, ao ritmo e intensidade de trabalho e à responsabilidade pelas tarefas que aparecem de forma importante nos artigos revisados, porém sem indicação de repercussão na saúde dos trabalhadores.

Há necessidade da realização de pesquisas no campo da Saúde do Trabalhador, com a participação dos trabalhadores e suas entidades representativas, que evidenciem a relação saúde-doença em sericicultores no Brasil, com vistas à prevenção e à promoção da sua saúde, bem como para preencher as lacunas de conhecimento relacionadas ao impacto da sericicultura no trabalho e no ambiente. 


\section{Contribuições de autoria}

Todas as autoras contribuíram de maneira substancial no projeto e delineamento, no levantamento de dados, na sua análise e interpretação bem como na elaboração do texto, na sua revisão crítica e aprovação final da versão a ser publicada.

\section{Referências}

ALMEIDA, G. E. G. Fumo: servidão moderna e violação dos direitos humanos. Curitiba: Terra de Direitos, 2005. Disponível em: <http://actbr.org.br/uploads/ conteudo/594_Fumo_serv_moderna_livro.pdf $>$. Acesso em: 25 mar. 2013 .

ATAÍDE, L. T. Diagnóstico da atividade sericícola na base territorial do Paraná centro e identificação de gargalos tecnológicos. 2007. 130 f. Dissertação (Mestrado em Agronomia)-Programa de Pós-graduação em Agronomia, Centro de Ciências Agrárias, Universidade Estadual de Londrina, Londrina, 2007.

BRANCALHÃO, R. M. C. Vírus entomopatogênicos no bicho-da-seda. Biotecnologia: Ciência e

Desenvolvimento, Cascavel, v. 24, p. 54-58, 2002. Disponível em: <http://www.biotecnologia.com.br/ revista/bio24/virus.pdf> . Acesso em: 2 mar. 2013.

BRASIL. Ministério do Trabalho e Emprego. Portaria $\mathrm{n}^{\mathrm{o}} 3214$, de julho 1978. Normas regulamentadoras de segurança e saúde no trabalho. NR-15: atividades e operações insalubres. Diário Oficial da União, Brasília, DF, 6 jul. 1978. 82 p. Disponível em: <http://acesso. mte.gov.br/data/files/8A7C816A47594D040147D14EAE 840951/NR-15\%20(atualizada\%202014).pdf > . Acesso em: 29 out. 2014.

. Ministério do Trabalho e Emprego. Portaria $\overline{\mathrm{n}^{\circ}} 86$, de 3 de março de 2005. Aprova a norma regulamentadora de segurança e saúde no trabalho na agricultura, pecuária, silvicultura, exploração florestal e aqüicultura. Diário Oficial da União, Brasília, DF, 4 mar. 2005. 54p. Disponível em: http://portal.mte.gov.br/ images/Documentos/SST/NR/NR31.pdf > Acesso em: 29 out. 2014.

. Banco Nacional de Desenvolvimento Econômico e Social - BNDES. Commodities agrícolas: evolução recente de preços. Rio de Janeiro, 2011. 16p. (Informativo Técnico Seagri, 4). Disponível em: <http://www.bndes.gov.br/SiteBNDES/export/sites/ default/bndes_pt/Galerias/Arquivos/conhecimento/ informativo_SEAGRI/InformativoSEAGRI_04_2011. pdf>. Acesso em: 29 out. 2014.

. Companhia Nacional de Abastecimento CONAB. Proposta de preços mínimos: safra 2013/14 produtos de inverno, regionais e leite. Brasília, 2013. 126p. Disponível em: <http://www.conab.gov.br/ OlalaCMS/uploads/arquivos/13_11_22_15_42_37_pm imverno_13_14.pdf $>$. Acesso em: 29 out. 2014.

BRATAC FIAÇÃO DE SEDA. Fiação de Seda Bratac S.A. Londrina, 2002. Vídeo institucional. Disponível em: <http://www.bratac.com.br/bratac/pt/index.php>. Acesso em 28 out. 2014.

. Nossa história. Londrina, 2013. Disponível em: <http://www.bratac.com.br/bratac/pt/index.php?GTR VARS_acesso $=$ modulos/conteudo/detTexto.php\&GTR_ VARS_codtexto=1\&>. Acesso em: 4 maio 2013.

CORREA, M. J. M. A construção social do silêncio epidemiológico do benzenismo: uma história negada. 2008. 178 f. Dissertação (Mestrado em Serviço Social)-Faculdade de Serviço Social, Universidade Católica do Rio Grande do Sul, Porto Alegre, 2008. Disponível em: <http://repositorio.pucrs. br/dspace/bitstream/10923/5118/1/000407788Texto\%2BCompleto-0.pdf $>$. Acesso em: 10 maio 2013. $</$ ths $>$.

CUNHA, R. M. Analises técnica e energética da secagem combinada no processamento de casulo do bicho-da-seda de Bombyx mori L. 2007. $71 \mathrm{f}$. Dissertação (Mestrado em Agronomia)-Faculdade de Ciências Agronômicas, Universidade Estadual Paulista, Botucatu, 2007.

FARIA, N. M. X. et al. Processo de produção rural e saúde na Serra Gaúcha. Cadernos de Saúde Pública, Rio de Janeiro, v. 16, n. 1, p. 115-128, 2000. http:// dx.doi.org/10.1590/S0102-311X2000000100012. PMid:10738156.

FEHLBERG, M. F.; SANTOS, I. S.; TOMASI, E. Prevalência e fatores associados a acidentes de trabalho em zona rural. Revista Saúde Pública, São Paulo, v. 35, n. 3, p. 269-275, 2001. http://dx.doi.org/10.1590/S003489102001000300009 .

INSTITUTO NACIONAL DO CANCER - INCA. Formol ou formaldeído: fatores de risco. Brasília. Disponível em: <http://www.inca.gov.br/conteudo_view. asp?id=795> . Acesso em: 15 jul. 2013.

INSTITUTO BRASILEIRO DE GEOGRAFIA E ESTATÍSTICA - IBGE. Produção da pecuária municipal 2011. Brasília, 2011. Disponível em: <ftp://ftp.ibge. gov.br/Producao_Pecuaria/Producao_da_Pecuaria_ Municipal/2011/ppm2011.pdf>. Acesso em: 10 jūn. 2013.

JUSBRASIL. MPT ajuíza ações para condenar indústrias fumageiras a indenizar fumicultores. Curitiba, 2007. Disponível em: <http://mpt-prt09.jusbrasil.com.br/ noticias/1383672/mpt-ajuiza-acoes-para-condenarindustrias-fumageiras-a-indenizar-fumicultores $>$. Acesso em: 4 maio 2013. 
LACAZ, F. A. C. O campo da Saúde do Trabalhador: resgatando conhecimentos e práticas sobre as relações trabalho-saúde. Cadernos de Saúde Pública, Rio de Janeiro, v. 23, n. 4, p. 8-16, 2007. http://dx.doi. org/10.1590/S0102-311X2007000400003.

LAURELL, A. C.; NORIEGA, M. Processo de produção e saúde: trabalho e desgaste operário. São Paulo: HUCITEC, 1989.

LIU, Z. et al. Identification and characterization of an arginine kinase as a major allergen from silkworm (Bombyx mori) larvae. International Archives of Allergy and Immunology, Basel, v. 150, n. 1, p. 8-14, 2009. http://dx.doi.org/10.1159/000210375. PMid:19339797.

MARCELINO, A. G. Desenvolvimento tecnológico da extração da sericina e preparação de nanopartículas para aplicação em cosméticos. 2008. 146 f. Dissertação (Mestrado em Engenharia Química)-Faculdade de Engenharia Química, Universidade Estadual de Campinas, Campinas, 2008.

MENEGUIM, A. M. et al. Influência de cultivares de amoreira Morus spp. sobre a produção e qualidade de casulos de bicho-da-seda, Bombyx mori L. (Lepidoptera: Bombycidae. Neotropical Entomology, Londrina, v. 36, n. 5, p. 670-674, 2007. http://dx.doi.org/10.1590/S1519566X2007000500006.

MIRANDA, J. E.; BONACIN, G. A.; TAKAHASHI, R. Produção e qualidade de folhas de amoreira em função da época do ano e de colheita. Scientia Agricola Piracicaba, v. 59, n. 3, p. 499-505, 2002. Disponível em: <http://www.scielo.br/pdf/sa/v59n3/10582.pdf>. Acesso em: 7 mar. 2013.

MUNHOZ, R. E. F. et al. A influência de cultivares de amoreira adubadas sobre características biológicas e produtivas do bicho-da-seda (Bombyx mori L.). Arquivos de Ciências Veterinárias e Zoologia da UNIPAR, Umuarama, v. 12, n. 2, p. 129-134, 2009.

NAKAZAWA, T.; UMEGAE, Y. Sericulturist's lung disease: hypertensitivity pneumonitis related to silk production. Thorax, London, v. 45, n. 3, p. 233234, 1990. http://dx.doi.org/10.1136/thx.45.3.233. PMid:2330556.

NOGUEIRA, G. M. Hidrogéis e filmes de fibroina de seda para a fabricação ou recobrimento de biomateriais. 2010. 126 f. Tese (Doutorado em Engenharia Química)Universidade Estadual de Campinas, Campinas, 2010.

OLIVEIRA, D. A. O pequeno agricultor familiar e suas relações com o complexo agroindustrial. Boletim de Geografia, Maringá, v. 8, n. 1, p. 27-40, 1990. Disponível em: <http://periodicos.uem.br/ojs/index. php/BolGeogr/article/view/12219>. Acesso em: 7 mar. 2013.

PARANÁ (Estado). Secretaria de Estado da Agricultura e do Abastecimento - SEAB. Safras 2010/11 e 2011/12. Relatório Takii. Curitiba, 2013. p. 67. Disponível em: <http://www.agricultura.pr.gov.br/arquivos/File/ complexo_da_seda/seric1011e1112.pdf > . Acesso em: 15 out 2014.
PAULINO, E. T. Terra e vida: a geografia dos camponeses no norte do Paraná. 2003. 430 f. Tese (Doutorado em Geografia)-Faculdade de Ciências e Tecnologia, Universidade Estadual Paulista, Presidente Prudente, 2003.

REZENDE, J. M. P. Caso SHELL/CYANAMID/BASF: epidemiologia e informação para o resgate de uma precaução negada. 2005. 206 f. Tese (Doutorado em Saúde Coletiva)-Universidade Estadual de Campinas, Campinas, 2005.

SABBAG, O. J.; NICODEMO, D.; OLIVEIRA, J. E. M. Custos e viabilidade econômica da produção de casulos do bicho-da-seda. Pesquisa Agropecuária Tropical, Goiânia, v. 43, n. 2, p. 187-194, 2013. http://dx.doi. org/10.1590/S1983-40632013000200004.

SANTANA, V. S. Saúde do Trabalhador no Brasil: pesquisa na pós-graduação. Revista de Saúde Pública, São Paulo, v. 40, n. spe, p. 101-111, 2006. http://dx.doi. org/10.1590/S0034-89102006000400015.

SANTOS, S. A.; VIDIGAL, P. G.; MERLINI, L. S. A criação do Bombyx mori (bicho- da- seda) e as principais doenças. Arquivos de Ciências Veterinárias e Zoologia da UNIPAR, Umuarama, v. 14, n. 1, p. 57-64, 2011.

SILVESTRE, M. P.; CAPITANI, E. M. Aspectos da legislação brasileira e da vigilância epidemiológica das doenças ocupacionais respiratórias.

Pneumologia Paulista, São Paulo, v. 24, n. 11, p. 6-11, 2010. Disponível em: <http://www. sociedadeclementeferreira.org.br/images/BoletimSetembro10.pdf>. Acesso em: 11 maio 2013.

SOUZA, M. T.; SILVA, M. D.; CARVALHO, R. Revisão integrativa: o que é e como fazer. Einstein, São Paulo, v. 8, n. 1, p. 102-106, 2010. http://dx.doi.org/10.1590/ S1679-45082010RW1134.

TAKAHASHI, R.; TAKAHASHI, K. M.; TAKAHASHI, L. S. Sericicultura: uma promissora exploração agropecuária. 2. ed. Jaboticabal: Funep, 2009. 135 p.

VIJAYABHASKARARAO, A. et al. An epidemiological and environmental survey on occupational health hazards during silk production and processing. In: ENVIRONMENTAL HEALTH CONFERENCE, 2013, Boston, USA. Philadelphia: Elsevier, 2013. Disponível em: <http://elsevier.conference-services.net/ resources/247/3306/pdf/ENVR2013_0709.pdf>. Acesso em: 20 maio 2013.

WANG, X.; ZHENG, S.; ZHANG, H. A study of occupational asthma and specific IgE in sericulture workers. Zhongguo Yi Xue Ke Xue Yuan Xue Bao, Beijing, v. 16, n. 5, p. 323-327, 1994. PMid:7720120.

WANI, K. A.; JAISWAL, Y. K. Health hazards of rearing silk worms and environmental impact assessment of rearing households of Kashmir, India. Nature Environment and Poluttion Technology, India, v. 10, n. 1, p. 85-90, 2011. 